\title{
NEUTRALIDADE DE REDE: NÚCLEO DE DIREITO FUNDAMENTAL A INTERNET
}

\section{Alessandro de Almeida Santana Souza* Daniel Barile da Silveira**}

Resumo: O presente trabalho tem como objetivo identificar a neutralidade de rede como sendo Direito Fundamental à internet. À luz do art. $5^{\circ}$, parágrafo $2^{\circ}$, da Constituição Federal e da Lei do Marco Civil da Internet, o trabalho pretendeu demonstrar que não basta que os cidadãos tenham acesso à internet, mas a tudo que o mundo digital tem a ofertá-las sem nenhum um tipo de restrição. Utilizou-se o método dedutivo e a metodologia de pesquisa bibliográfica, documentos eletrônicos e legislação. Concluiu-se que a neutralidade de rede é um núcleo do direito fundamental à internet.

Palavras-chave: Direito fundamental. Garantia fundamental. Marco civil da internet. Liberdade de rede. Neutralidade de rede.

\section{NEUTRALITY OF NETWORK: CORE OF FUNDAMENTAL LAW TO THE INTERNET}

\begin{abstract}
The present work aims to identify network neutrality as Fundamental Right to the Internet. In light of art. $5^{\circ}$, paragraph $2^{\circ}$, of the Federal Constitution and the Civil Law of the Internet, the work aimed to demonstrate that it is not enough that citizens have access to the Internet, but to everything the digital world has to offer them without any kind of restriction . We used the deductive method and the methodology of bibliographic research, electronic documents and legislation. It was concluded that net neutrality is a core of the fundamental right to the internet.
\end{abstract}

Keywords: Civil domain of the internet. Freedom of network. Fundamental right. Fundamental guarantee. Network neutrality.

\section{INTRODUÇÃO}

O presente trabalho tem como objeto de estudo a neutralidade de rede como núcleo essencial de Direito Fundamental à internet. Essa neutralidade imprime a ideia de que não pode o provedor de internet limitar a liberdade de acesso do usuário a determinados conteúdos

\footnotetext{
* Mestrando do curso de Direito da Universidade de Marília-UNIMAR. Especialista em Direito Processual pela PUC-MG. Graduado em Direito pela Universidade do Estado de Mato Grosso. Advogado. E-mail: souza.alessandro@outlook.com.br

** Pós-doutorando em Democracia e Direitos Humanos pela Universidade de Coimbra. Doutor e mestre em Direito pelo programa de pós-graduação da Faculdade de Direito da UnB. Professor do programa de doutorado e mestrado em Direito da Universidade de Marília. Professor do programa de pós-graduação e do curso de graduação em Direito do UniToledo (Araçatuba/SP). Advogado e consultor jurídico em Direito Público.
}

Revista Brasileira de Direitos e Garantias Fundamentais | e-ISSN: 2526-0111 | Porto Alegre | v. 4 | n. 2 | p. $01-17$ | Jul/Dez. 2018 
por ele selecionados. Recentemente nos Estados Unidos da América a Comissão Federal de Telecomunicações aprovou medida que desobriga as empresas a manterem a neutralidade da internet.

$\mathrm{Na}$ prática, essa garantia evita que provedores manipulem a oferta de produtos e/ou serviços de acesso internet semelhante ao que acontece com os 'pacotes de TV à cabo'. Assim, à luz do art. $5^{\circ}$, parágrafo $2^{\circ}$, da Constituição Federal e da Lei do Marco Civil da Internet, o trabalho pretendeu demonstrar que não basta que os cidadãos tenham acesso à internet, mas a tudo que o mundo digital tem a ofertá-las sem nenhum um tipo de restrinção.

Muito se fala que a internet se tornou um direito fundamental na sociedade contemporânea. O Poder Judiciário cada vez mais tem incrementado ferramentas que facilitam o acesso do cidadão e dos operadores do direito aos conteúdos e serviços ofertados. Diante dessa perspectiva, o trabalho percorre o caminho teórico dos direitos fundamentais para demonstrar que além do acesso à internet, a neutralidade, que assegura o acesso a conteúdo irrestritamente, deve ser assegurado por se tratar núcleo essencial de direito fundamental.

Nos Estados Unidos da América, a agência reguladora Comissão Federal de Telecomunicações determinou o fim da igualdade de tratamento do tráfego de dados na internet. Assim, faz-se necessário o seguinte questionamento: a neutralidade de internet/rede pode ser considerado um núcleo de direito fundamental do cidadão?

No Brasil a neutralidade da internet está prevista na Lei n. $12.965 / 14$, que regula o uso da internet por meio da previsão de princípios, garantias, direitos e deveres para quem usa a rede, bem como da determinação de diretrizes para a atuação do Estado. Assim, à luz do art. $5^{\circ}$, parágrafo $2^{\circ}$, da Constituição Federal e da Lei do Marco Civil da Internet, o trabalho pretendeu demonstrar que não basta que os cidadãos tenham acesso à internet, mas a tudo que o mundo digital tem a ofertá-las sem nenhum um tipo de restrição.

A internet tornou-se um fenômeno social diante da facilidade de acesso, da universalidade de estrutura, da sua descentralização, da velocidade de transmissão da informação e a dupla via em que essa informação é transmitida, distinguindo-se dos meios de comunicação tradicional em massa.

Para a obtenção dos resultados almejados pelo trabalho, a pesquisa utilizou referência bibliográfica, abrangendo obras especializadas acerca dos direitos fundamentais. $\mathrm{O}$ 
método de abordagem seguido foi o dedutivo, abrangendo o fenômeno, fato concreto e a teoria, de forma intercalada. Ao final, conclui-se que a neutralidade de rede é um núcleo do direito fundamental à internet, o qual proporciona a todas as pessoas a liberdade de ter acesso a todo e qualquer conteúdo independentemente do pacote contratado.

\title{
2. DIREITO DE LIBERDADE COMO VERTENTE DE ACESSO LIVRE À REDE
}

O direito à liberdade é um instituto caro que foi conquistado pela sociedade e é considerado direito de primeira dimensão dentre as diversas dimensões dos direitos fundamentais. As liberdades de expressão e comunicação são sustentáculos da liberdade em si, dos direitos civis e políticos e da cidadania.

Ensina o português Paulo Ferreira da Cunha (2007, p. 9) que:

\begin{abstract}
Assim, a Liberdade, pelo menos a liberdade civil e política, começa, em grande medida, com a liberdade de expressão e comunicação. Uma vez assegurado o pressuposto dos direitos todos que é a vida, garantida a integridade física e psíquica $q . b$., e a liberdade geral de movimentos (sem constrições gritantes, sem cativeiro), o momento primeiro de livre desenvolvimento da personalidade em que se analisa a dignidade humana em acção, será o livre interagir com o seu semelhante.
\end{abstract}

Por meio da internet não se trata de meramente circular mensagem nesse espaço, mas de dotar esse espaço de valores significativos por cada pessoa, tendo acesso à tudo que está no mundo virtual, considerado a "reprodução do mundo real". Isso porque a pessoa humana é concebida, diria Gregorio Peces-Barba (1993, p. 61): "como um ser de eminente dignidade, caracterizado por sua razão e por sua liberdade. Esse reconhecimento exige o respeito e um tratamento do homem como sujeito, cuja independência e liberdade têm de ser garantidas na vida social".

O Direito a informação pode ter conotações de liberdade de emissão de conteúdo, acesso a dados por ação própria de pesquisa, e finalmente, direito a recepção de elementos ou mensagens informativas. Presume-se que, primeiramente, por parte do Estado, mas também particulares que detenham e/ou transmitam informação (CUNHA, p. 168).

No Estado Democrático de Direito, o acesso à informação é uma ferramenta essencial que representa poder. $\mathrm{O}$ manuseio da informação na internet, salvo determinadas exceções em razão da segurança, deve se dar de maneira aberta e livre. O Estado não pode ser

Revista de Direito Tributário e Financeiro | e-ISSN: 2526-0138 | Porto Alegre | v. 4 | n. 2 | p. 01 - 17 | Jul/Dez. 2018 
a ameaça a direitos civis dos indivíduos para, em nome da segurança, tender ao autoritarismo e restringir determinados direitos. O poder de polícia do Estado que ameaça a liberdade em suas diversas modalidades é o mesmo que quebra constantemente a barreira da vida privada dos cidadãos.

$\mathrm{O}$ acesso de forma livre e espontânea pelo indivíduo representa uma das vertentes da liberdade, que é um direito fundamental. Acerca desse instituto, Daniel Barile da Silveira argumenta:

Como vivemos em uma sociedade pluralista, formada por diversas crenças, valores e concepções de vida, definir direitos de forma universal com referência a valores que pesam mais que outros, destrói com qualquer possibilidade de afirmação do indivíduo enquanto ser dotado de liberdade de escolha, pois vincula seus direitos com o senso geral da sociedade sobre uma hierarquia de valores pré-fixada. Cada pessoa, assim, tem direito de desenvolver-se sem a interferência da sociedade [...]

Para o pleno desenvolvimento humano, a liberdade traduz a ideia de que no campo fático das relações que se realizam ações,

\begin{abstract}
Em sendo a liberdade um atributo indispensável à configuração do próprio modo de ser humano em sua plenitude, a convivência em sociedade requer o convívio das múltiplas liberdades. Para que isso seja possível, e necessário limites que possibilitem a todos e a cada um o exercício da liberdade de forma responsável (GOMES, 2011, p. 208).
\end{abstract}

No entendimento de Barreto Junior (2007, p. 345), a liberdade de manifestação do pensamento e de expressão:

\begin{abstract}
A disciplina do uso da internet no Brasil deve garantir a liberdade de expressão, comunicação e manifestação de pensamento, tal como determina a Constituição. Se já existe esta determinação na Constituição por quê repeti-la na lei infraconstitucional? Qual é o sentido? Devemos caminhar a interpretação em busca do que já foi construído ou estamos buscando algo novo? O objetivo desse trabalho é atualizar esses princípios a novas práticas de uma sociedade totalmente diversa daquela de 1988.
\end{abstract}

Assim, na exegese que propõe o Marco Civil, deve-se analisar a liberdade de expressão, como "o direito de externar ideias, opiniões, juízos de valor, em suma, qualquer manifestação do pensamento humano". Paulo Bonavides (2008, p. 303) ensina:

\footnotetext{
Revista de Direito Tributário e Financeiro | e-ISSN: 2526-0138 | Porto Alegre | v. 4 | n. 2 | p. 01 - 17 | Jul/Dez. 2018
} 
O homem porém não vive concentrado só em seu espírito, não vive isolado, por isso mesmo que por sua natureza é um ente social. Ele tem a viva tendência e necessidade de expressar e trocar suas ideias e opiniões com os outros homens, de cultivar mútuas relações, seria mesmo impossível vedar, porque fora para isso necessário dissolver e proibir a sociedade.

Contudo, o conceito de liberdade vem, ao longo do tempo, modificando-se de acordo com a evolução da sociedade (PASSI; SOARES, p. 436). A liberdade reflete felicidade ao indivíduo dando total significância a existência humana, de modo que a restrição da liberdade de acesso ao conteúdo virtual em grau e gênero, isto é, tudo o que consta no mundo cibernético, representa detrimento do direito à liberdade.

\section{MARCO CIVIL DA INTERNET: PRINCÍPIOS, FUNDAMENTOS E INCLUSÃO SOCIAL E DIGITAL}

A Lei n. 12.965/2014 é conhecida como a regra que instituiu o 'Marco Civil da Internet', e estabeleceu princípios, garantias, direitos e deveres para o uso da internet no Brasil. Em seu bojo de trinta e dois artigos busca regular o manuseio e aplicações da internet em todo o território nacional.

Os princípios explícitos estão organizados no artigo $3^{\circ}$ da lei, distribuídos em oito incisos:

\footnotetext{
Art. $3^{-}$A disciplina do uso da internet no Brasil tem os seguintes princípios:

I - garantia da liberdade de expressão, comunicação e manifestação de pensamento, nos termos da Constituição Federal;

II - proteção da privacidade;

III - proteção dos dados pessoais, na forma da lei;

IV - preservação e garantia da neutralidade de rede;

V - preservação da estabilidade, segurança e funcionalidade da rede, por meio de medidas técnicas compatíveis com os padrões internacionais e pelo estímulo ao uso de boas práticas;

VI - responsabilização dos agentes de acordo com suas atividades, nos termos da lei; VII - preservação da natureza participativa da rede;

VIII - liberdade dos modelos de negócios promovidos na internet, desde que não conflitem com os demais princípios estabelecidos nesta Lei.

Parágrafo único. Os princípios expressos nesta Lei não excluem outros previstos no ordenamento jurídico pátrio relacionados à matéria ou nos tratados internacionais em que a República Federativa do Brasil seja parte.
}

Princípios funcionam como bússolas do ordenamento jurídico. Têm como principal função direcionar as atividades executiva, legislativa e jurisdicional do Estado servindo como verdadeiros paradigmas para a sociedade civil como um todo. São os nossos "heróis", em uma

\footnotetext{
Revista de Direito Tributário e Financeiro | e-ISSN: 2526-0138 | Porto Alegre | v. 4 | n. 2 | p. 01 - 17 | Jul/Dez. 2018
} 
alusão aos seres mitológicos da Grécia antiga.

Hobsbawm (2008, p. 123) ensina que o Marco Civil se inicia com o comando legal de que nele se estabelecem os princípios, garantias, direitos e deveres para o uso da internet no Brasil. O autor ressalta que tal comando pressupõe um equívoco do legislador, uma vez que quem estabelece princípios, garantias, direitos e deveres para quaisquer usos e tecnologias é a Constituição Federal do Brasil, e menciona:

O Marco Civil é uma legislação infraconstitucional que deveria implementar e regulamentar a Constituição. Contudo, não é isso que ocorre. Muitas linhas se seguirão abaixo para constatar que o Marco Civil repete descontextualizadamente princípios, garantias, direitos e deveres constitucionais sem aprofundá-los para as questões e problemas existentes de suas inserções nas tecnologias de informação e comunicação. (2008, p. 124).

Para Paesani (2013, p. 321), o marco civil gastou tintas e tintas para reeditar princípios e regulamentações já existentes no ordenamento jurídico e que, invariavelmente, já eram utilizadas para resolver questões e problemas de internet, e poderia ter avançado mais na determinação de conteúdo material.

Os princípios citados acima demonstram que o Marco Civil pretende ser uma carta de direitos, uma constituição para as tecnologias de informação e comunicação. Portanto, os direitos declarados na Constituição Federal garantidores da dignidade humana são reafirmados, como a liberdade de expressão, a personalidade e por consequência a proteção à intimidade e privacidade, a livre iniciativa, a defesa do consumidor, o exercício da cidadania e a orientação na finalidade social do objeto regimentado.

O Marco Civil da Internet busca promover, conforme art. $4^{0^{1}}$, institutos capazes de realizarem a inclusão social e digital, ou seja, traduz na execução dos princípios e direitos, não se tratando de numerus clausus. Há de se permitir que novos objetivos, que não constam do texto legal, sejam construídos e apresentados nas decisões judiciais.

A promoção poderá ser pautada pelos incisos do citado artigo e poderão orientar o legislador na formulação de políticas públicas e reinterpretação das leis vigentes. Por

\footnotetext{
${ }^{1} \mathrm{O}$ artigo de lei elenca quatro incisos descrevendo que a disciplina do uso da internet no Brasil tem por objetivo a promoção do direito de acesso à internet a todos; do acesso à informação, ao conhecimento e à participação na vida cultural e na condução dos assuntos públicos; da inovação e do fomento à ampla difusão de novas tecnologias e modelos de uso e acesso e da adesão a padrões tecnológicos abertos que permitam a comunicação, a acessibilidade e a interoperabilidade entre aplicações e bases de dados.
}

Revista de Direito Tributário e Financeiro | e-ISSN: 2526-0138 | Porto Alegre | v. 4 | n. 2 | p. 01 - 17 | Jul/Dez. 2018 
exemplo, o art. 154 da Lei Geral de Telecomunicações ${ }^{2}$, que versa sobre o compartilhamento de redes de telecomunicações, poderá ser implementado para ampliar o acesso de todos à internet. Por outro lado, práticas e leis que instituam obstáculos e empecilhos à implementação desses princípios deverão ser alteradas especificamente à luz da manutenção da internet.

\section{O DIREITO FUNDAMENTAL A INTERNET E O SEU NÚCLEO ESSENCIAL}

Muitos autores nacionais e internacionais já tratam o tema da internet como sendo um direito fundamental. Ela - a internet - tornou-se essencial não só para as atividades estatais como principalmente para os indivíduos. A vida pública e privada, na última década, estão nitidamente interligadas por meio da internet, e, sob essa perspectiva, se abordará adiante que o acesso à internet é fundamental, mas que além disso, a neutralidade revela-se como um verdadeiro núcleo essencial desse direito.

\subsection{O ACESSO À INTERNET COMO DIREITO FUNDAMENTAL}

Segundo Bobbio (2004, p. 53): “o desenvolvimento da técnica, transformação das condições socioeconômicas, a ampliação do conhecimento e a intensificação dos meios de comunicação poderão (...) criar condições para o nascimento de novos carecimentos e novas demandas de liberdade e poderes". Há muitos pontos de conexão entre a internet e os direitos fundamentais.

É certo que a atual Constituição brasileira contempla, em especial no título II, primícias de direitos fundamentais, abrangendo direitos individuais e coletivos, direitos sociais, de nacionalidade e políticos. Como já dito anteriormente, não se cuida de uma numeração exaustiva, conforme se pode observar do seu próprio texto, na dicção do parágrafo $2^{\circ}$, do artigo $5^{\circ}$, a cláusula de abertura do catálogo, que prevê a possibilidade de inserção no sistema jurídico brasileiro de outros direitos decorrentes da estrutura e dos princípios adotados, bem como dos tratados e convenções internacionais, além dos direitos fundamentais previstos fora do título II ao longo do texto constitucional.

\footnotetext{
${ }^{2} \mathrm{O}$ citado artigo menciona que "as redes de telecomunicações poderão ser, secundariamente, utilizadas como suporte de serviço a ser prestado por outrem, de interesse coletivo ou restrito".
}

Revista de Direito Tributário e Financeiro | e-ISSN: 2526-0138 | Porto Alegre | v. 4 | n. 2 | p. 01 - 17 |
Jul/Dez. 2018 
Um direito é considerado formalmente fundamental quando recebe tal qualificação por ordem expressa do legislador-constituinte, enquanto o caráter de direito materialmente fundamental depende, sobretudo, de tal garantia ser parte integrante da Constituição material, em face de sua essência e substância exigirem dito reconhecimento (SARLET, 86-87).

Diante desse quadro, busca-se a equivalência do direito àqueles tidos como formalmente fundamentais, ou seja, sua relevância, a substância e conteúdo. Essa relevância de acesso à internet se revela seja no direito prestacional como no de defesa. A liberdade que subsidia o direito a livre expressão e a liberdade informativa está essencialmente ligada a comunicação entre as pessoas e o intercâmbio de informações.

Os direitos de participação decorreram de direitos de liberdade a partir do aprofundamento das exigências sociais que grupos excluídos passam a pleitear um aprimoramento dos direitos de igualdade, exigindo tal ação do Estado. Como lembra Emerson Oliveira (2015, p. 8),

Nessa linha, a ampliação de direitos fundamentais decorrente desse processo de exigência das forças sociais não apenas atribui aos indivíduos aumento de seu alcance, mas melhoria da qualidade de seu alcance. Assim, para grupos até então excluídos são garantidos direitos inerentes aos demais membros da sociedade; e para os direitos conferidos, há um incremento de sua substância. O conflito nessa luta por reconhecimento propugnada pelas classes excluídas se torna o motor populsor tanto para o aumento do alcance quanto para a ampliação do conteúdo material do direito.

É sabido que a sociedade é dinâmica, e o direito deve transformar-se para acompanhar essas mudanças. Quando se promulgou a atual constituição a internet apenas começava a popularizar-se timidamente no Brasil. Mas logo esse cenário sofreu modificações, dentro dessa seara os direitos fundamentais se encontram em processo permanente de formação, conforme avança a humanidade nos aspectos de desenvolvimento da ciência e tecnológico.

Indubitavelmente, a rede mundial de computadores detém um lugar de destaque no rol de direitos fundamentais na medida em que oportuniza as liberdades de expressão e comunicação, gerando a efetiva manifestação de direitos civis e/ou políticos, proporcionando a condensação da cidadania por meio de uma democracia participativa à luz do pluralismo informativo e o livre acesso à circulação da informação.

$\mathrm{O}$ direito fundamental de acesso à internet reflete como um mandamento de 
proibição direcionado ao Estado e particulares para que se abstenham de restringir, de qualquer forma desproporcional ou não justificada, o acesso da pessoa à conexão de rede de mundial de computadores. Não se pode tratar esse direito como uma mera questão decorrente de contrato entre partes - a pessoa física e o fornecedor desses serviços. O mundo virtual é, em sua essência, um novo espaço social, o qual oportuniza diversas maneiras de trocar experiências entre os usuários.

Outro ponto a se destacar é da igualdade material que pode ser inserida no direito de conexão a fim de promover a liberdade de acesso à todas as pessoas. Por essa razão, aqueles que encontram-se dentro das limitações físicas, de manuseio ou econômicas de acesso poderão exigir do Estado a execução dessa tarefa para suprir a desigualdade. Segundo Krell (1999, p. 240):

\begin{abstract}
Os direitos fundamentais sociais não são direitos contra o Estado, mas sim direitos por meio do Estado, exigindo do Poder Público certas prestações materiais. O Estado, por meio de leis, atos administrativos e da criação real de instalações de serviços públicos, deve definir, executar e implementar, conforme as circunstâncias, as chamadas "políticas sociais" (educação, saúde, assistência, previdência, trabalho, habitação) que facultem o gozo efetivo dos direitos constitucionalmente protegidos.
\end{abstract}

Segundo dados do Instituto Brasileiro de Geografia e Estatística - IBGE $^{3}$ - são cerca de 63 milhões de brasileiros que não acessam a internet. As pessoas que não sabem usar a rede mundial de computadores, segundo o levantamento, representa $37,8 \%$, seguido de $37,6 \%$ de pessoas que não têm interesse em aprender a se conectar.

Diante disso, ao tratar de direito defesa e de prestação em se tratando de direitos fundamentais, Mendes (2007, p. 248) explica os dois institutos e alerta para a importância da participação ativa do Estado:

\begin{abstract}
Se os direitos de defesa asseguram as liberdades, os direitos prestacionais buscam favorecer as condições materiais indispensáveis ao desfrute efetivo dessas liberdades. Os direitos a prestação supõem que, para a conquista e manutenção da liberdade, os Poderes Públicos devem assumir comportamento ativo na sociedade civil.
\end{abstract}

A eficácia do direito estabelece a obrigação do Estado de incluir essa questão, por

\footnotetext{
${ }^{3}$ Os dados foram coletados em 2016, segundo a Pesquisa Nacional por Amostra de Domicílios (Pnad) Contínua. Disponível em: <https://www.ibge.gov.br/estatisticas-novoportal/sociais/trabalho/17270-pnadcontinua.html?=\&t=o-que-e>. Acesso em: 07 de set. 2018.
}

Revista de Direito Tributário e Financeiro | e-ISSN: 2526-0138 | Porto Alegre | v. 4 | n. 2 | p. 01 - 17 |
Jul/Dez. 2018 
exemplo, nas políticas públicas de educação. Tal direito funciona como norma objetiva obrigando a inclusão digital, que consiste em disponibilizar terminais de acesso e dar capacitação àqueles que não dispõe de instrução mínima para fazer o uso adequado da internet.

\subsection{O FIM DA NEUTRALIDADE DE REDE NOS ESTADOS UNIDOS DA AMÉRICA E O MARCO CIVIL DA INTERNET NO BRASIL - NEUTRALIDADE DE REDE COMO NÚCLEO ESSENCIAL DE DIREITO FUNDAMENTAL}

Este ano entrou em vigor nos Estados Unidos da América a regulamentação federal editada pela Federal Communications Comission - FCC - colocando fim a neutralidade de rede. A agência funciona como uma espécie de estatal reguladora semelhante a Agência Nacional de Telecomunicações do Brasil - ANATEL.

O fim da neutralidade da rede, conforme concebido pela FCC, permite aos provedores de internet criar "vias rápidas", "vias lentas" e "vias bloqueadas", para forçar os usuários e os proprietários de websites e aplicativos, bem como fornecedoras concorrentes de conteúdo, a pagar uma espécie de "pedágio" para trafegar livremente na internet. A neutralidade de rede é o conceito segundo o qual provedores não podem privilegiar ou restringir o acesso a qualquer pacote de dados na rede.

Dos 50 Estados americanos, 27 se opuseram, inicialmente, contra a medida federal e iniciaram suas próprias estratégias para manter intactas as proteções à neutralidade da rede. Washington foi o primeiro Estado a editar lei estadual que restabelece a neutralidade da rede em seu território.

No Brasil, os principais eixos temáticos tratados pelo Marco Civil da Internet estão a privacidade, a neutralidade da rede e a inimputabilidade da rede. Tais princípios visam garantir os direitos e liberdades democráticas de internautas frente a ações abusivas de governos (nacionais e estrangeiros) e empresas prestadoras de serviços.

Prevista no artigo $9^{\circ}$, a neutralidade estabelece que todos os dados que trafegam na rede devem receber o mesmo tratamento das empresas provedoras de acesso, sem distinção de origem, destino, serviço, conteúdo ou dispositivo. Sobre a neutralidade de rede, dá ensinamento claro Hartmann (2007, p. 27):

Revista de Direito Tributário e Financeiro | e-ISSN: 2526-0138 | Porto Alegre | v. 4 | n. 2 | p. 01 - 17 | Jul/Dez. 2018 
Como restrições entendemos tanto o impedimento físico de acesso, como o controle deste, na forma de limitação dos sites que poderão ser visualizados, bem como na forma de censura. $\mathrm{O}$ acesso deve ser inicialmente livre, privilegiando a possibilidade indiscriminada de troca de informações, tanto aquelas que o indivíduo recebe guardando-se aí certa similaridade com o direito a informação - como aquelas que envia - existindo então maior proximidade com o direito a liberdade de expressão.

Nessa linha, a neutralidade da internet ou rede é o núcleo essencial do direito a internet. A restrição, limitação ou redução de seu conteúdo implica em prejuízo de tal direito. Como já tratado em parágrafos anteriores, a liberdade é um direito caro e que está nitidamente ligado ao direito fundamental de acesso a internet. Nas palavras de Amartya Sem (2000, p. 33) "ter mais liberdade melhora o potencial das pessoas para cuidar de si mesmas e para influenciar o mundo, questões centrais para o processo de desenvolvimento."

A Constituição Federal de 1988 não contempla expressamente a proteção do núcleo essencial dos direitos fundamentais. Contudo, em que pese o texto constitucional brasileiro não ter feito essa manifestação expressa, é inequívoco que a proteção do conteúdo essencial dos direitos fundamentais decorre do próprio modelo garantístico utilizado pelo constituinte. A não admissão de um limite ao legislador tornaria inócua qual qualquer proteção fundamental.

Em comparação ao direito alemão, Häberle (2003, p. 219-220) ensina que o art. 19.2 da Lei Fundamental alemã, segundo o qual "em nenhum caso um direito fundamental poderá ser afetado em sua essência”, possui natureza declaratória. Segundo o autor, o referido artigo teria expressado de modo declarativo simplesmente o que resulta de uma interpretação adequada do direito fundamental afetado.

Daí pode-se afirmar que o princípio de proteção ao núcleo essencial do direito fundamental surgiu com a finalidade de estabelecer, em especial para o legislador, um limite para a limitação dos direitos fundamentais. Ordenou a forma de atuação do legislador quando o mesmo objetivar a restrição de um determinado direito fundamental, sob pena de ter seu produto considerado inconstitucional.

A não admissão de um limite ao afazer legislativo tornaria inócua qualquer proteção fundamental. O princípio da proteção do núcleo essencial destina-se a evitar o esvaziamento do conteúdo do direito fundamental decorrente de restrições descabidas, desmesuradas ou desproporcionais.

Revista de Direito Tributário e Financeiro | e-ISSN: 2526-0138 | Porto Alegre | v. 4 | n. 2 | p. 01 - 17 | Jul/Dez. 2018 
Ensinam Sarlet e Fensterseifer apud Canotilho (2010, p. 18):

\begin{abstract}
Por certo, é nessa perspectiva que se colaciona lição de CANOTILHO, sustentando que o núcleo essencial dos direitos sociais concretizado pelo legislador encontra-se constitucionalmente garantido contra medidas estatais que, na prática, resultem na anulação, revogação ou aniquilação pura e simples desse núcleo essencial, de tal sorte que a liberdade de conformação do legislador e a inerente auto-reversibilidade encontram limitação no núcleo essencial já realizado.
\end{abstract}

Canotilho (2003, p. 339) realizou a teoria de proibição do retrocesso baseada na garantia do "núcleo essencial" do direito já realizado, ou seja, nenhuma alteração legislativa (seja infraconstitucional, seja do próprio poder constituinte derivado) poderia violar um direito adquirido (em sentido amplo), o que ensejaria "clara violação do princípio da proteção da confiança e da segurança dos cidadãos no âmbito econômico, social e cultural, e do núcleo essencial da existência mínima inerente ao respeito pela dignidade da pessoa humana".

Isso demonstra que a proibição de retrocesso se revela a partir do pensamento de proteção dos direitos fundamentais, especialmente no que tange ao seu núcleo essencial, na medida em que a tutela e o exercício efetivo de tais direitos só são possíveis onde esteja assegurado um nível mínimo de segurança jurídica e previsibilidade do próprio ordenamento jurídico objetivo, bem como dos direitos subjetivos dos cidadãos. Qualquer atentado exercido contra o núcleo essencial de determinado direito fundamental, por sua vez, reflete sua inconstitucionalidade da medida legislativa ou administrativa (SARLET; FENSTERSEIFER, 2010, p. 12).

$\mathrm{Na}$ esfera dos direitos fundamentais, Sarlet e Fensterseifer (2010, p. 12) destacam que ao legislador e aos órgãos estatais são incumbidos de um dever permanente de desenvolvimento e concretização dos direitos fundamentais, de modo que "não permite, em qualquer hipótese, a supressão ou restrição desses de modo a invadir o seu núcleo essencial, bem como, atentar, de outro modo, às exigências do princípio da proporcionalidade".

O legislador não pode, assim, uma vez concretizado determinado direito social no plano da legislação infraconstitucional, ainda que com efeitos meramente futurológicos, retroagir e, mediante uma supressão ou mesmo relativização, afetar o núcleo essencial legislativamente concretizado de determinado direito fundamental. É em primeira linha o núcleo essencial dos direitos sociais que vincula o Poder Público no âmbito de uma proteção contra o retrocesso e que, portanto, representa aquilo que efetivamente se encontra protegido.

Revista de Direito Tributário e Financeiro | e-ISSN: 2526-0138 | Porto Alegre | v. 4 | n. 2 | p. 01 - 17 | Jul/Dez. 2018 
Nesse sentido, a neutralidade de internet alinha-se à recomendação da Organização das Nações Unidas, explica Bezerra e Waltz (2014, p. 167):

\begin{abstract}
O conceito de neutralidade da rede alinha-se à resolução da Organização das Nações Unidas que aponta o acesso à internet como um Direito Humano. O Pacto Internacional Sobre Direitos Civis e Políticos, adotado pelo Brasil em 1992, estabelece no $2^{\circ}$ parágrafo do Art. 19 que "toda pessoa terá direito à liberdade de expressão; esse direito incluirá a liberdade de procurar, receber e difundir informações e ideias de qualquer natureza, independentemente de considerações de fronteiras, verbalmente ou por escrito". A ONU entende que qualquer restrição ou bloqueio à internet constitui uma violação do artigo 19, mesmo por conta de infrações de direitos autorais, como acontece em países como Reino Unido e França.
\end{abstract}

A essência da neutralidade de rede está relacionada a condutas aceitáveis e não aceitáveis por parte dos provedores de conexão, sendo proibidos a discriminação e bloqueio de aplicativos, a priorização de aplicativos, vedada a degradação do trafego na rede e obrigatória a transparência aos usuários sobre as medidas de gerenciamento da rede. Como bem argumenta Lawrence Lessing (2015, p. 230): "todo conteúdo seja tratado de maneira isonômica e trafegue na Internet sob a mesma velocidade".

Nesse sentido, assinala Ramos (2014, p. 165-187) acerca desse instituto:

(i) o princípio da neutralidade da rede impõe a provedores de acesso a obrigação de não bloquear o acesso de usuários a determinados sites e aplicações, sendo também vedado aos provedores de acesso arbitrariamente reduzir a velocidade ou dificultar o acesso a aplicações específicas; (ii) a neutralidade da rede impede a cobrança diferenciada para acesso a determinados conteúdos e aplicações, sendo livre a cobrança de tarifas diferenciadas conforme a velocidade de acesso ou volume de banda utilizada; e (iii) os provedores de acesso devem manter práticas transparentes e razoáveis a respeito de seus padrões técnicos de gerenciamento de tráfego.

Por certo que as ofertas comerciais e os modelos de cobrança de acesso a rede devem preservar uma internet única, de natureza aberta, plural e diversa, compreendida como um meio para a promoção do desenvolvimento humano, econômico, social e cultural, contribuindo para a construção de uma sociedade inclusiva e não discriminatória.

Para o Estado e para o provedor a neutralidade não representa a violação de qualquer direito ou qualquer prejuízo significativo, porém, quando invertida a situação, percebe-se desde logo no plano teórico que o ônus recai sobre os indivíduos.

\title{
5. CONSIDERAÇÕES FINAIS
}

Revista de Direito Tributário e Financeiro | e-ISSN: 2526-0138 | Porto Alegre | v. 4 | n. 2 | p. 01 - 17 | Jul/Dez. 2018 
A partir do presente estudo pode se averiguar que a internet representa um meio de comunicação que se transformou em uma nova seara pública, abastecendo um direito social com reflexo no exercício de diversos direitos fundamentais.

$\mathrm{O}$ acesso a rede, conjugada com os requisitos que caracterizam o direito material fundamental, revela-se como direito fundamental à luz da Constituição Federal de 1988. Inúmeras situações sociais são alcançadas, por exemplo, o exercício da cidadania, a partir do livre acesso a rede mundial de computadores pelos cidadãos.

Assim, o Marco Civil constitui um elemento fundamental para a promoção da liberdade de expressão, combate à censura e promoção de direitos constitucionais da internet, muito embora há que se avançar em termos políticos, legais e sociais. A neutralidade de rede está inserida em um contexto de preocupação, uma vez que novos serviços surgem e competem com outros aplicativos, inclusive do próprio provedor de conexão, e esses aplicativos exigem cada vez mais maior quantidade de dados.

Diante desse cenário, o estudo demonstrou que qualquer ação que atente contra a neutralidade de rede é passível de atingir o núcleo essencial do direito fundamental à internet. A neutralidade de rede não representa para o Estado e nem para o provedor de serviços nenhum prejuízo, mas o fim da neutralidade acarreta prejuízos ao cidadão, limitando o exercício de muitos outros direitos, principalmente, o da liberdade.

\section{REFERENCIAS}

BEZERRA, Arthur Coelho; WALTZ, Igor. Privacidade, neutralidade e inimputabilidade da internet no brasil: avanços e deficiências no projeto do marco civil. Disponível em: < https://seer.ufs.br/index.php/eptic/article/viewFile/2276/1954>. Acesso em: 07 de set. 2018.

BRASIL. Lei n ${ }^{\circ}$ 9.472, de 16 de julho de 1997. Disponível em:

<http://www.planalto.gov.br/ccivil_03/LEIS/L9472.htm>. Acesso em: 07 de set. 2018.

BRASIL. Lei n. 12.965, de 23 de abril de 2014. Disponível em: < http://www.planalto.gov.br/ccivil_03/_Ato2011-2014/2014/Lei/L12965.htm>. Acesso em: 05 de set. 2018 .

Revista de Direito Tributário e Financeiro | e-ISSN: 2526-0138 | Porto Alegre | v. 4 | n. 2 | p. 01 - 17 | Jul/Dez. 2018 
ARTESE, Gustavo. Marco Civil da Internet: Análise Jurídica sob uma Perspectiva Empresarial. São Paulo: Quartier Latin, 2015.

BARRETO JUNIOR, Irineu Francisco. A relevância do conceito sociedade da informação para a pesquisa jurídica. In: PAESANI, Liliana Minardi. Direito na sociedade da informação. São Paulo: Atlas, 2007.

BOBBIO, Norberto. A Era dos Direitos. Nova ed. Rio de Janeiro: Elsevier, 2004.

BONAVIDES, Paulo. Ciência política. 12. ed. São Paulo: Malheiros, 2008.

CANOTILHO, José Joaquim Gomes. Direito constitucional e teoria da constituição. 7. ed. Coimbra: Almedina, 2003.

CUNHA, Paulo Ferreira da. Direito à informação ou deveres de protecção informativa do Estado? In: SARLET, Ingo Wolfgang. Direitos Fundamentais, informática e comunicação: algumas aproximações. Porto Alegre: Livraria do Advogado, 2007.

GOMES, Sergio Alves. Hermenêutica constitucional: um contributo à construção do Estado Democrático de Direito. Curitiba: Juruá, 2011.

HÄBERLE, Peter. La garantía del contenido esencial de los derechos fundamentales. Madrid: Dykinson, 2003.

HOBSBAWM, Eric. A Era dos Extremos. São Paulo: Companhia das Letras, 2008. MENDES, Gilmar Ferreira. Curso de direito constitucional. São Paulo: Saraiva, 2007. KRELL, Andreas J. Realização dos direitos fundamentais sociais mediante controle judicial da prestação dos serviços públicos básicos (uma visão comparativa). Out/dez, ano 36, n 144, Brasília: Revista de Informação Legislativa, 1999.

PAESANI, Liliana Minardi. O Direito na Sociedade da Informação III - A Evolução do Direito Digital. São Paulo: Atlas, 2013.

Revista de Direito Tributário e Financeiro | e-ISSN: 2526-0138 | Porto Alegre | v. 4 | n. 2 | p. 01 - 17 | Jul/Dez. 2018 
PASSI, R.C.Z.Q.; SOARES, M. A. S. A concepção republicana de liberdade: A necessidade da participação do homem na política. In: XXIV Encontro Nacional do SOARES RAMOS, Pedro Henrique. Neutralidade da rede e o Marco Civil da internet: um guia para interpretação. In: SALOMÃO LEITE, George (coord.); LEMOS, Ronaldo (coord.). Marco Civil da Internet. São Paulo: Atlas, 2014.

CONPEDI, 2016, Brasília. Teorias da Democracia e Direitos Políticos?, 2016. Acesso em: 04 de set. 2018.

SARLET, Ingo Wolfgang. A eficácia dos direitos fundamentais. $9^{\mathrm{a}}$ Ed. Porto Alegre: Livraria do Advogado, 2007.

SARLET, Ingo Wolfgang; FENSTERSEIFER, Tiago. Notas sobre os deveres de proteção do estado e a garantia da proibição de retrocesso em matéria (socio)ambiental. Disponível em: < http://www.planetaverde.org/arquivos/biblioteca/arquivo_20131207162429_2438.pdf>. Acesso em: 07 de set. 2018.

SILVEIRA, Daniel Barile da. Paradigmas de Interpretação Constitucional: um desafio ao entendimento das sociedades modernas. Revista Urutágua (Online), v. 11, p. 11, 2006. Acesso em: 04 de set. 2018.

SEN, Amartya Kumar. Desenvolvimento como liberdade. São Paulo: Companhia das Letras, 2000

OLIVEIRA, Emerson Ademir Borges de. A estética da luta por reconhecimento na efetivação dos direitos humanos. Argumentum, v. 16, p. 55-72, 2015.

HARTMANN, Ivar Alberto Martins. $O$ acesso à internet como direito fundamental. Disponível em: < http://www.egov.ufsc.br/portal/sites/default/files/ivar_hartmann.pdf >. Acesso em: 07 de set. 2018.

Revista de Direito Tributário e Financeiro | e-ISSN: 2526-0138 | Porto Alegre | v. 4 | n. 2 | p. 01 - 17 | Jul/Dez. 2018 
PECES-BARBA, Gregorio. Derecho y Derechos Fundamentales. Madrid: Centro de Estudios Constitucionales, 1993. 